\title{
A STUDY OF SOMATIC IDEAS IN VARIOUS PSYCHOSES.
}

By THEODORE A. HOCH, M. D.,

Assistant Physician and Pathologist, Worcester Insane Hospital,

Worcester, Mass.

"In its primitive form pain is always physical, that is to say connected with external or internal sensations. Sufficiently precise as regards superficial parts of the body, especially the skin, its localization is more vague when it is seated in the deeper parts, the viscera, the instruments of organic life. In the last case, when the pain is of internal and non-peripheral origin, coming from the great sympathetic or related vagus nerve, it is accompanied by a state of anxiety, of depression or of anguish, which we shall often encounter and which frequently causes it to be said that 'it seems to the patient that the workings of nature within him are suspended.' " The above quotation is taken from Ribot ( $I$ ), and in a concise form differentiates real pain from the more vague visceral feelings which, in the insane, so frequently serve as a foundation for somatic sensations.

Of the many delusions entertained by the insane, perhaps none are more distressing than those pertaining to their physical welfare. Even in normal individuals, slight bodily ailments cause greater or less mental depression and anxiety, and worry and grief are accompanied by trivial physical pains or exaggerate those already present. Of still greater moment is the personal welfare of the individual who suffers imaginary tortures and is surrounded by imaginary dangers, especially when hampered by faulty reasoning associated with an inability to separate the real from the unreal. The basis of hypochondriacal ideas may be some visceral disease, peripheral neuritis, etc., which gradually becomes elaborated in the patient's mind far beyond the actual existing condition; or the idea may have no physical foundation whatever and is built up of previous delusions which serve as a means of misinterpreting normal sensations or occurrences. Many mental traits have been shown to have a close relation to the 
motor mechanism and bodily functions; and aside from the deliria, definite psychoses have been described accompanying visceral diseases.

The relation of mental changes to visceral disturbances was clearly demonstrated by Head (2). He showed the presence of well-marked hallucinations and depressed affects in many diseases, especially of the heart, lungs, and abdominal viscera. His observations were made on patients without a previous psychosis and in whom the mental manifestations arose when the bodily disease was well advanced. The degree of mental derangement bore a direct relation to the intensity of the disease. These psychoses are usually transitory, but often they are the initial symptoms of a prolonged psychosis which may far overreach the physical disease. Depressions of varying intensity are often observed which are wholly out of proportion to the gravity of the disease. Hallucinations, delusions of various kinds and self-accusations, are often present with little or no insight into the condition.

Fischer (3) studied the relation of heart disease to various psychoses and concludes that: (a) heart disease may be the exciting cause in precipitating psychoses in predisposed individuals; (b) the uncompensated heart lesions may induce a psychosis in individuals not predisposed, as a result of disturbance of cerebral circulation and chemical blood changes; (c) the psychoses (under b) are of the type of hallucinatory confusion. The color of the hallucinations is given by the abnormal sensations. If prolonged they may end in dementia.

Krafft-Ebing (4) mentions the following somatic causes for the neurasthenic conditions: bodily over-exertion, toxic influences, syphilis, debilitating effects of the puerperium, chronic local diseases, gastro-intestinal diseases, movable kidneys, diseases of the male and female genitalia, diseases of the nose, unhygienic sexual life, anæmia, poor diet, anti-fat cures, mineral water cures, cold water cures, and hot baths. From this great variety of causes it is evident that individual idiosyncrasies play a great part in the production of neurasthenic states in predisposed neurotic persons.

Kiernan (5) gives a list of diseases which are said to cause, modify, or cure insanity. He mentions more particularly rheumatism, gout, typhoid fever, measles, acute pneumonia, acute 
nephritis, and variola, as exerting a favorable influence, perhaps with too much stress, since he goes as far as to say "Paretic dementia is said to have been cured by variola," and, later, "Phthisis renders paretics more or less suspicious."

We frequently have an opportunity to observe the influence which some intercurrent disease has upon a pre-existing psychosis, causing either an exacerbation or amelioration of the mental symptoms. A manic attack may readily turn into a delirium or some grave disease may subdue an excitement.

Ill health is a common general etiological factor assigned in mental diseases. With few exceptions it is rather one of the many acute exciting causes which precipitate the psychosis in a previously neurotic individual. The presence of a physical disease in such persons brings about a concentration of attention upon themselves. They become worried and depressed and soon have permanent morbid somatic ideas with little or no foundation. Psychoses in which there is worry, anxiety and depression, as in melancholia, and the depressed phases of manic-depressive insanity and dementia præcox, may have an acute or sub-acute onset during some illness. In women menstrual disturbances are frequent exciting causes.

In I869, Mayer (6) studied the influence of menstruation on mental disturbances and gives a table showing the development, or aggravation of mental symptoms before or after menstruation. 2100 women were examined and 400 , or 19.05 per cent, showed some alteration. He gives the following table:

\begin{tabular}{|c|c|}
\hline Cases. & Per Cent. \\
\hline $\begin{array}{l}\text { Cephalæa and prosopalgia } \ldots \ldots \ldots \ldots \ldots \ldots \ldots \ldots \ldots 66 \\
\text { Cardialgia with or without nausea } \ldots \ldots \ldots \ldots \ldots \ldots 67\end{array}$ & $\begin{array}{l}21.50 \\
16.75\end{array}$ \\
\hline Hysterical convulsions $\ldots \ldots \ldots \ldots \ldots \ldots \ldots \ldots \ldots 2$ & 13.00 \\
\hline Hemicrania $\quad \ldots \ldots \ldots \ldots \ldots \ldots \ldots \ldots \ldots \ldots \ldots \ldots \ldots$ & II.25 \\
\hline General feeling of weakness.................... & 9.25 \\
\hline Præcordial Angst and dyspnœa...............23 & 5.75 \\
\hline Feeling of cold $\ldots \ldots \ldots \ldots \ldots \ldots \ldots \ldots \ldots, \ldots \ldots$ & 5.50 \\
\hline 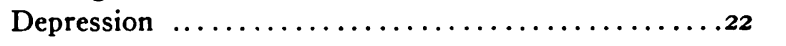 & $5 \cdot 5$ \\
\hline Hyperæsthesia and anæsthesia of peripheral nerves.. I5 & 3.75 \\
\hline$\ldots \ldots \ldots \ldots \ldots \ldots \ldots \ldots \ldots \ldots \ldots \ldots \ldots, 8$ & 2.00 \\
\hline 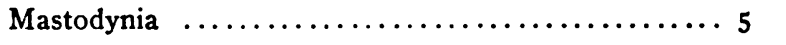 & $\mathbf{1 . 2 5}$ \\
\hline 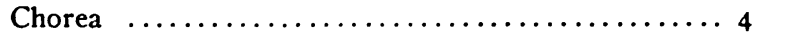 & 1.00 \\
\hline 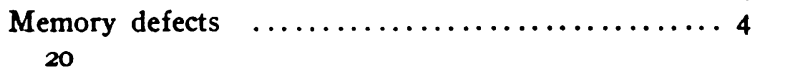 & 1.00 \\
\hline
\end{tabular}




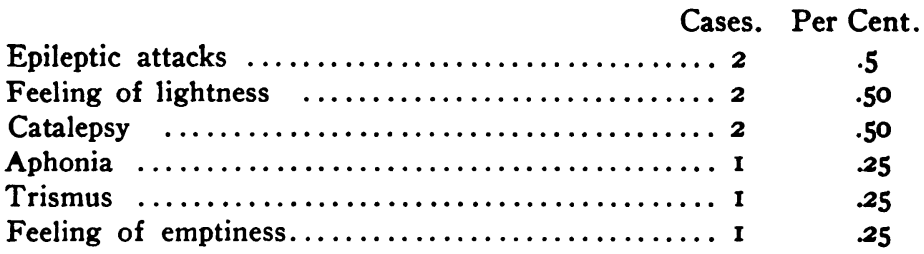

Where a physical disease co-exists with a depressing psychosis, the patient may entirely lose sight of his mental trouble and become so absorbed in his physical condition that in a short time firm rooted somatic delusions are elaborated.

Somatic delusions belong primarily to the various states of depression. They may arise in patients who are depressed and agitated, and who spenil much time in self-analysis. If the depression is accompanied by a suicidal attempt by taking poison, etc., the patient is thereafter convinced that his throat and stomach are damaged beyond repair.

In psychoses with a paranoic coloring, somatic ideas are more commonly engrafted upon some delusion. The patients experience peculiar feelings which are attributed to electricity, hypnotism, etc., and are associated in their minds at once with the other persecutory ideas. In alcoholic psychoses of this nature, various paræsthesias or pains along the nerve trunks, may underlie these ideas. At times they may develop insidiously. Often tactile hallucinations, or paræsthesias of a sexual nature, receive faulty interpretations on the basis of other delusions. The occurrence of hallucinations of taste and smell in connection with delusions of a sexual nature is very striking.

Somatic ideas are at times very changeable, depending upon the environments, or they may even be a part of a general euphoric condition, pleasant in nature, and associated with other delusions of grandeur, centering about their own personality. Klein (7) sought to refer the euphoristic states of general paralysis to paræsthesias of an agreeable nature.

Previous existing physical disease may be the direct cause of these ideas, and lighter forms of peculiar subjective sensations, such as hot flashes, numbness and prickling may exist with a real basis, but on a delusional principle. Where a peculiar sensation is experienced by a paranoic patient, however mild or changeable, 
it is another link in the chain of persecution. These somatic ideas usually appear late in paranoic conditions and some unknown and mysterious force is sought in explanation of the sensations. Somatic ideas are often transitory symptoms which may be fabrications, pure and simple, or which may have as a result a prominent though short period of affect without insight. The expression of these ideas may be only once or variable, showing momentary concentration of some thought to the ego.

Wollenberg (8) divides hypochondriacal ideas into two large groups, viz., the constitutional and the accidental-the latter he subdivides into those originating from (I) abnormal ideas; (2) those following some exhaustion, or illness; and (3) those depending on a disturbance of the cœnæsthesia. Those depending on a disturbance of the cœnæthesia are really physiological, inasmuch as they depend upon natural changes such as the climacterium. Our cases are all of the accidental type. They are, however, largely the result of some functional brain alteration where normal physiological sensations are transformed into pathological somatic ideas; in other words, they are illusions of feeling.

While pleasure and pain are the most marked phases of pure subjectivity, somatic sensations in the insane, as a rule, may be said to be those of discomfort, pain, and anguish, especially those relating to internal sensations, where the feelings are with difficulty located definitely, but which are referred to some special organ or region, depending upon the enlivened imagination and defective judgment of a diseased mentality. Even where organs are involved which, when stimulated, produce pleasurable or voluptuous sensations in the normal individual, the feeling is one of irritation and is coupled with abuse on a delusional basis, and referred to outside influences, such as electrical, hypnotic, etc. These sensations, when referring to the sexual organs, are invariably attributed to external causes, on a basis of delusions of persecution and are reacted to by threats, violence, and irritability. They are complained of freely with a view of apprehending the perpetrator and of stopping the abuse. Unfortunately these delusions are very stable and in themselves suggest a chronic condition and an unfavorable outcome and are found in the degenerative psychoses, appearing early in dementia pracox of 
the paranoic type, in the paranoic states following the involution and less commonly in alcoholics. In the latter the brain itself is commonly the seat of peculiar sensations. It is acted upon by a machine or some electrical device which is often blamed for the transmission of the hallucinations, putting the voices into the ears and projecting faces and pictures before the eyes.

The cutaneous sensations are usually quite definitely localized and more acutely painful than the visceral feelings and are sometimes limited to regions of certain nerve distributions. The various paræsthesias which may occur in normal individuals are magnified and misinterpreted and the explanation is sought in electrical and other influences in the hands of an enemy. Neuritis in the course of alcoholic psychoses, also gastric crises and girdle pains in tabetic general paralytics, are examples of this type. Often rheumatic pains in the joints are misinterpreted on a delusional basis, as electric shocks thrown upon the patient by unseen persecutors.

The milder sensations in the skin gradually merge into slight tactile hallucinations and sensory illusions with mild reaction on the part of the patient. Later the delusion may become so fixed and tenacious that it is accepted as a fact without further reasoning, even if abnormal sensations no longer exist. Thus a patient may pass through the acute phase of a beginning dementia præcox, stubbornly refusing food because he has no stomach, and leading a wretched and miserable existence with great depression and worry. Gradually he lapses into a more indifferent state, perhaps passes the stomach tube on himself for his daily food, and soon begins to eat. The former domineering idea is dropped from the foreground and a condition of apathy and dementia supervenes with but little thought and concern about himself. If asked about his stomach he may answer with a smile, "I have none," but will continue to eat. Again there are deteriorated patients who get on well from day to day but who show a multiplicity of somatic delusions, transitory and changeable in character, without affect and without altering much the course of their daily life; whose physical health is good, but whose minds are in a dilapidated condition; whose judgment is faulty and who are unable to draw logical conclusions or deductions. Their mental sphere is so narrow as to misinterpret occurrences and actions of others; 
center them upon themselves and the distorted imagination produces, among other ideas, delusions somatic in nature.

The more highly specialized senses,--hearing, sight, taste, and smell,-may develop a very prominent hallucinosis, but are less often accompanied by somatic or subjective sensations. To an olfactory hallucination may be added a feeling of irritation of the nasal mucous membrane, by some imaginary powder thrown into the air. A biting and gnawing of the tongue is often associated with hallucinations of taste, especially when underlying delusions of poisoning.

It is rarer, however, to have pronounced somatic sensations of the eyes and ears coincident with visual or auditory hallucinations. At the most a rumbling sensation is felt in the ear, or a blinding light is experienced in the eye.

Edmund Parrish (9) says that hallucinations of taste and smell are very difficult to distinguish from illusions and also from hyperæsthesia of these sensations, and, on the whole, are infrequent: for instance, resulting from disease of the mouth or tongue. Olfactory hallucinations are seldom of an agreeable nature. They seldom appear alone but are frequently associated with other sensory fallacies. They are frequently found in local diseases of the ovaries and of the reproductive organs in general.

The somatic ideas of the paranoic states have a strong delusional basis with but little or no actual physical disease of the parts involved. The ideas are very flexible and the details are altered or receive new interpretations under different environments. Thus strong hypnotic or electrical influences often cease abruptly for a brief period after the admission to the hospital. Soon, however, a new system is evolved or the old one is more elaborated. Either former persecutors are able to transmit their powers over long distances, or they use the nurses, physicians, etc., as their agents, or new tortures are inflicted by those who come in daily contact with the patient. By gradual evolution the original delusion may no longer exist.

Hallucinations of the cutaneous sensibility, of the organic senses, and the like, are not easily distinguished from paræsthesias and however important they may be in building up the mental delusions they are, as a rule, too vague to influence the content of thought directly. It is only when a darkened intelligence 
seizes them as a basis for a new conception of the ego and the environment that they become of primary significance.

In the words of Ribot (I0), it is the organic sense, the sense of the body, usually vague and obscure, but at times clear in all of us, that excites in each animal the basis for its psychic individuality.

Attention depends on the mental state. Pathologically, spontaneous attention may become a fixed idea. The center of attraction is established which little by little gains complete control of the consciousness; then it grows to be a perpetual pre-occupation, an incessant inception of the state of each organ and the products of each function.

The ideas founded on a general breakdown of the body, a definite disease, pain, or some distinct physical etiology are accompanied by a deep depression, fear, anxiety, and a hypochondriacal condition and are not influenced by a change of environment. The patient is very introspective and gives as proof of his particular assertions the general emaciation of his body. Coincident with physical improvement there is usually a parallel disappearance of the somatic delusions. Such ideas, in themselves, call for a favorable prognosis modified by the general mental and physical state of the patient.

While nearly all forms of mental disease show somatic traits, from the mildest paræsthesias to the more profound ideas of absent vicera and délire de negation, certain types seem to conform to a definite symptom-complex.

A study of the following table, which comprises an analysis of 1564 cases, will serve to show the frequency of somatic ideas in the various psychoses. In 221 cases, or a little over I2 per cent, ideas of a hypochondriacal nature were present, which in many instances bore an intimate and important relation to the other symptoms.

Psychoses.

Dementia pracox ........... 357

General paralysis $\ldots \ldots \ldots \ldots$ Igr

Senile dementia $\ldots \ldots \ldots \ldots \ldots$ I69

Paranoic condition .......... I57

Manic-depressive insanity ...... I06

Alcoholic insanity $\ldots \ldots \ldots \ldots \ldots$ I06

$\begin{array}{cr}\begin{array}{c}\text { Bomatic ideas } \\ \text { present. }\end{array} & \begin{array}{r}\text { Per } \\ \text { cent. } \\ 80\end{array} \\ 22.40 \\ \text { 18 } & 9.42 \\ 8 & 4.73 \\ 41 & 26.11 \\ 7 & 6.60 \\ 19 & 17.92\end{array}$




\begin{tabular}{|c|c|c|c|}
\hline \multicolumn{2}{|c|}{$\begin{array}{l}\text { No. of cased } \\
\text { examined. }\end{array}$} & \multirow{2}{*}{$\begin{array}{c}\text { Somatic idees } \\
\text { present. } \\
\text { I }\end{array}$} & \multirow{2}{*}{$\begin{array}{r}\text { Per } \\
\text { cent. } \\
\text { I.69 }\end{array}$} \\
\hline Organic dementia $\ldots \ldots \ldots \ldots \ldots$ & 59 & & \\
\hline$\ldots \ldots \ldots \ldots \ldots \ldots$ & 52 & 42 & 80.76 \\
\hline Epileptic insanity & 33 & $\mathbf{I}$ & 3.03 \\
\hline Imbecility $\quad \ldots \ldots \ldots \ldots \ldots \ldots \ldots$ & 25 & 一 & \\
\hline Constitutional inferiority $\ldots \ldots \ldots$ & 24 & 2 & 8.33 \\
\hline Delirium (various forms) . & 24 & $\mathbf{I}$ & 4.16 \\
\hline Habitual drunkards $\ldots \ldots \ldots \ldots$ & 14 & 一 & \\
\hline Polyneuritic psychoses $\ldots \ldots \ldots \ldots$ & 7 & $\mathbf{I}$ & 14.28 \\
\hline Morphinism $\quad \ldots \ldots \ldots \ldots \ldots \ldots$ & 5 & 一 & \\
\hline Traumatic insanity $\quad \ldots \ldots \ldots \ldots$ & 5 & 一 & \\
\hline Hysterical insanity $\ldots \ldots \ldots \ldots \ldots$ & 5 & - & \\
\hline Huntington's chorea $\ldots \ldots \ldots \ldots$ & 4 & - & \\
\hline$\ldots \ldots \ldots \ldots \ldots$ & & 22 I & 12.85 \\
\hline
\end{tabular}

To let 12.85 per cent represent the number of times somatic ideas were found, is subject to some error. It represents accurately the number as far as the records show, but many of these patients have reached a stable state of deterioration and either the history of the onset is not accessible or they were residents of the hospital for years before accurate records were kept. In many of these patients, no doubt, somatic ideas were relatively as prominent as many other unrecorded delusions which must have existed in some form at the beginning of the psychosis.

Melancholia.-In the differential diagnosis of melancholia from other psychoses the question is often asked, "Has the patient any somatic ideas?" which thereby implies that the presence of these ideas establishes beyond any doubt the existence of melancholia. The question should rather be: "What is the nature of the somatic ideas; what part do they play; what relation are these ideas to the physical condition of the patient; how much affect is shown; and how does the patient react to these ideas?" With the extreme self-absorption and self-analysis, apprehension and worry over himself, we expect the patient suffering from melancholia to worry over his physical as well as mental welfare and this is what actually occurs. Ill health may underlie the initial anxiety and apprehension of the patient. Often the mental agitation begins insidiously. The patient's mind is in a state of unrest, the origin, cause and nature of which even he cannot determine. He worries more and more. Some cause must be found. Often 
[Oct.

he remembers some trivial misdeed of his youth, dwells upon it and soon convinces himself that he committed a great sin and this is the cause of his mental state. Another worries over home and children, fears something will befall them, that he cannot provide food for them, denies himself proper food, becomes a physical wreck and rapidly loses ground. With the wasting of his body he is able to prove that some physical cause is at the base of his trouble. With his mind centered on himself, the smallest ache, or pain, or feeling of indisposition, is greatly exaggerated in his own mind. Symptoms referable to the alimentary tract are apt to be present. Under normal conditions the patient might diagnose his case as one of "indigestion" or "biliousness," but now it has a more serious aspect. Food distresses him; something must be wrong; he is constipated and sure that the food is never digested and does not reach the intestines; perhaps the food does not reach his stomach; perhaps it drops into a hollow space; perhaps the stomach is closed off, etc. He is soon convinced that one of these must be the cause, and though the patient's intellect may be unimpaired and his judgment in other matters good, he cannot be shaken in his belief that something fearful ails him. At the height of these delusions, when the mind is centered on the ego, ideas emanating from without are absent or in the background. I have in mind a patient who was anxious and depressed, attempted suicide by drinking wood alcohol, worried over it and refused almost all nourishment for months because the wood alcohol caused her throat to contract and burned out her stomach and bowels. She came to the hospital, retained this idea until her husband visited her. After he left, she was confident that he was retained in the hospital and was being tortured. She heard him call her and heard his tormentors killing him, etc. She made no more mention of her somatic ideas but suddenly developed a prominent hallucinosis. She began to eat better, improved physically and mentally. When her husband visited her again she was allowed to see him leave the hospital and saw him walk away. She was then convinced and made a speedy recovery. During her psychosis she showed extreme affect in reaction to these ideas but after her recovery laughed at the absurdity of them. The hallucinosis began abruptly as the somatic ideas disappeared. They did not occur together. The 
only symptom common to both was the general worry, agitation, and apprehension, first for herself, later for her husband.

Less often delusions of a somatic nature develop rather suddenly. While worrying about himself the patient suddenly conceives the idea that there is a hole in his stomach, etc., and adheres to the idea with the same tenacity that is found in those patients in whom there was a gradual unfolding and elaboration of these ideas.

On the whole the prognosis in these cases is very favorable, especially where the ideas appear early, are in the foreground and not associated with hallucinations and prominent self-accusations; but they are dangerous, inasmuch as food refusal often accompanies these ideas and the debilitated condition soon leads to some fatal intercurrent disease. Where there is a gradual elaboration, the delusions are usually very stable, especially if the patients are weakened and run down, and the wasting of flesh proves to them the truth of the statement. In milder cases a generalization of the somatic ideas exists. A vague, indefinite depression and anxiety and some idea of ill health may exist.

Somatic ideas are sometimes the foremost symptom of melancholia. The sensations arise from within the body and in Wernicke's sense, are pure somatopsychoses. In the following instances there is a direct relation of the somatic ideas to previous physical states.

One patient with arteriosclerosis and mitral insufficiency, and suffering from hematuria, complained permanently with great affect that his heart did not beat; he had no pulse; worried over his kidneys; said he had syphilis and that his head was filled with bugs. Another patient became very much worried and depressed after an operation for cancer of the right breast. She attempted suicide because of an over-powering fear that she also had cancer of the stomach.

One patient was left very weak after a prolonged attack of influenza; a mild depression with a general hypochondriacal condition followed. Patent medicines were taken for stomach trouble, and finally firm-rooted ideas of poisoning and strong somatic ideas developed. Stomach and bowels gone; cannot swallow; food does no good, etc. In this case there was a slow 
development of symptoms (2 years). Little affect was shown and a mild deterioration took place.

Another patient began to worry greatly over her condition after she had undergone an ovariotomy and ventral suspension. She felt as if there were snakes in her abdomen and that her stomach had fallen to pieces. She displayed a marked affect, but improved greatly.

A similar case followed an operation for hemorrhoids. The patient thought that her bowels and stomach were full of fleas and insects, and had prominent delusions of reference and poisoning. She became irritable and showed a permanent strong reaction.

A patient suffering from uterine fibroids merged from a depressed condition into a paranoic state with prominent sexual delusions, also olfactory and gustatory hallucinations. She believed herself to be pregnant and thought that the tumor was decaying and passing away in the stools, causing the foul odor. These ideas remained permanent with a reaction of scolding and threatening. After taking a tonic which she knew contained iron, another patient became depressed and agitated. She refused food because the iron closed up her throat and caused her to burst open. She showed some improvement.

During the course of an anxious depression, another patient began to worry about his hernia. He refused food because he was " all swelled up " and was "burning up inside." At the same time he feared his home and family were being burned up. In a very apprehensive patient who had prominent auditory hallucinations and continually wailed:" $I$ believe there is something in my stomach; my food doesn't pass through; it's rotten," there was discovered at autopsy a cancer of the pylorus!

In some cases, however, pronounced physical diseases exist, which are totally ignored by the patient who evidently centers all his complaints about some previous pet idea. This reaction is more prominent in paranoic conditions. Thus a patient with overpowering ideas that her stomach was closed, her bowels never moved, her eyes were leaving, etc., never complained of the distressing cough, and dyspnœa of advanced pulmonary tuberculosis from which she was suffering.

Another patient disregarded completely the rapid emaciation 
and presence of cancer of the liver and gall-bladder, which appeared to cause great suffering, but retained to the end the ideas that she could never die, that she was a spirit, full of poisons and animals enough to kill all nations, brain gone and head full of hot sand and ashes, etc.

A patient suffering from asthma complained continually of her stomach and bowels and knew she could never die, but said nothing of her actual sickness.

Occasionally we meet with patients who suffer from attacks of cardiac incompensation which are accompanied by a feeling of "Angst" and great agitation and depression. One patient has been at this hospital during several such attacks. The mental symptoms subsided each time with the improvement of the heart.

The story which we hear from patients in whom the evolution of the somatic ideas has been gradual, i. e., in whom there has been a general disturbance of the cœnæsthesia, without any tangible basis, is much the same in every patient, differing only in degree. The visceral organs are complained of most constantly but the ideas are usually extremely absurd. There is a strong affect shown and the ideas are tenaciously held.

The somatic ideas present in the depressed phases of cases of manic-depressive insanity, while relatively uncommon, are very apt to originate from some occurrence or illness. A patient who accidentally swallowed a needle, took salts. This was supposed to have rusted the needle and caused the blood to decay. One patient complained that her eyes had sunk deep into her head after she had taken gas for extraction of teeth. Another patient was constipated and took 6 cathartic pills. A firm belief remained that the bowels were ruptured and the legs were rotting off.

Ideas of a somatic nature were absent in all manic phases of manic-depressive insanity.

DEMENTIA PRAcox.-In dementia pracox there is a dissolution of mind, parallel with the body, but neither is recognized. Comparative weights of the brain and other organs show a regression from the normal. This fact, however, cannot be correlated with the somatic ideas. Cases of dementia præcox show a multiplicity of ideas which are usually adhered to with considerable affect and elaborated on a basis of delusions. Patients often have a somato-psychic feeling of being drawn out, 
pulled out, muscles torn away, blood withdrawn, etc. These ideas often refer to beauty, face, or especially to the sexual organs. The affect is not so much in the form of worry, anxiety, depression, and hopelessness as of irritability, violence, and obscenity; not pleading for help or to be killed, but rather threatening if the supposed abuse is not stopped. They are not so apt to arise from actual physical disease but are often formed on the basis of delusions of poisoning through medicine, electricity or other power. The prognosis is not good. Eventually the delusion will cease, but dementia takes its place. The reaction is often quite marked in refusing food, but perhaps more from the idea of poisoning which is really at the root. As is often the case, the throat, stomach, and bowels first attract the patient's attention, or the idea may refer to the brain or sexual organs only, but the complaints vary. One thing to-day; another to-morrow. The absurdity never strikes the patient; attempts to reason are futile. He has no insight whatever. There is usually no foundation for his ideas and they are not within the bounds of possibilities. They can only in a vague way be said to be evidence or manifestations of a depressed condition, since they are associated more with anger than with sadness. The ideas originate usually when the disease is well-advanced and may be looked upon more as a sign of deterioration and an evidence of lack of judgment.

The scarcity of somatic ideas in old demented cases, following dementia præcox and other dementing psychoses, is very noticeable and natural. The patient has reached the stage of a vegetative existence. Nothing worries him, as he is too indifferent to think of his physical or mental condition. If somatic ideas were present in the beginning, they have faded with the other delusions. They are more persistent in psychoses where no deterioration is evident, where the intellect is unimpaired but where the judgment is faulty.

The somatic ideas in dementia præcox are often associated with a general alteration of the surroundings. Everything appears changed and the patient himself is different from formerly. He is an automaton, represents some other person, etc.

It is rare that a case of dementia præcox bases his ideas on some definite physical cause, or that such delusions are precipitated by some disease. If bodily disease co-exists with somatic 
delusions, the latter rarely have a direct bearing on the former. In the following two cases a psychosis seems to have been precipitated by external causes, and the contents of the delusions stand in close relation to the cause. In one patient, prominent hallucinations of smell followed poisoning by illuminating gas. There was also a feeling of the brain shaking in the head. The patient developed prominent delusions of influence and persecution, became expansive and reacted to her ideas by threats, noise, and violence.

The other patient had had an operation on her eyes and immediately became very suspicious of the physicians and nurses whom she suspected of cutting her body to pieces, separating soul from body, taking out her eyes, etc. After some time there was complete change of personality; she was Christ and the entire surroundings were unnatural; those about her were spirits, etc. A marked deterioration ensued.

The following examples are perhaps less specific and possibly largely accidental. A general hypochondriacal condition supervened in a patient who was anæmic and debilitated, and a depressed affect was manifest in reaction thereto; however, her complaints were absurd and variable. One day her head kept moving and her throat was stopped up; the next day wind collected about her heart, then she had brain fever, and so on. Another patient became worried and depressed during her first pregnancy, thought she had the worst diseases imaginable and was covered with filth. A strong depressed affect was present and rapid deterioration followed.

Many cases of dementia præcox attribute their mental and physical weakness to masturbation, and most of them are familiar with cheap literature on the subject. The onset is usually with worry and depression, the " mind becomes weak" and the "system run down." In the statements of various patients the following evil effects were thought to have resulted from masturbation: "paralysis of the right side; weight in the stomach; heart feeble; system loose and flabby; pressure on the brain which scatters the thoughts; head bulges; stomach, intestines, and nervous system in bad condition; burning up inside; feeling as if brain was leaving; becoming tall and shrinking to nothing; blood not circulating 
right ; change of identity; breasts bitten and milked; feeling of pregnancy," etc.

The reaction to such statements is indifferent and apathetic. The sensations may be spoken of often with but little affect or depression, but are sometimes attributed to electrical and hypnotic influences and intellectual as well as emotional deterioration is rapid.

Menstrual disorders similarly affect the content of the delusions. The patient often fears she is pregnant and frequently experiences peculiar abuses at night.

The following statements of patients, in whom no physical cause for the somatic delusion can be demonstrated, show extreme absurdity and variability. Often they are recited with a smile, usually with indifference and at times when coupled with delusions, they are accompanied by threats and violence.

I. "Fear of bleeding to death when urinating; throat filled up; thoughts flow from wrists; thoughts leave with breath; drawn up and made to go through peculiar motions."

II. "Bones and organs destroyed; spine worked down into rectum where he feels it; life falling through rectum; fæces full of human beings." (Apparently firm belief in them but inadequate reaction.)

III. "Blood goes out into atmosphere; head knocked off; shoulders gone; patients steal his blood; pieces taken out of his neck. Blown-up feeling; filled with tacks and wires." (Advanced deterioration.)

IV. "Losing his senses and parts of his body; pieces of flesh fall to the floor; holes in abdomen and things fall out." (Somatic ideas disappeared and pronounced apathy and dementia ensued.)

V. " Becoming ugly ; eyes not right ; skin bad ; hair on face." (Seclusive reaction at first, later dementia.)

Sensations of the following nature are attributed to electrical and other outside influences, and are accompanied by an aggressive threatening attitude.

"Muscles are torn from the back; tormented by pulling the arteries and drawing on the brain; peculiar forces affect tongue, eyes, ears, and character; muscles of neck, arms, and back are pulled; heart made to beat too fast; foam put into mouth; brain removed; body is used to bear children for others; machines 
break up her body; bore holes in her head; people put through her; heart jumps up and down; insides taken out every night," etc.

The source of such delusions is difficult to explain. When they are stable they might be traced to some peculiar disturbance of the cœnæsthesia, but where they are changeable, they are probably random statements which are of no special consequence to the patient, but happen to follow in this particular channel and are evidence of a deteriorating process.

AlCOHOLIC PSYCHOSES.-Chronic alcoholics who have reached a paranoic stage and whose existence is miserable on account of feelings of persecution, influence, and auditory hallucinations, often feel that electricity, hypnotism, or some machine, is working on them. They are suspicious and soon have evolved a complex system of delusions. Many, though not expressing some concrete somatic idea, suffer greatly from electric currents, machines and other power, giving them shocks, burning them, etc. These often refer to the stomach and brain. Usually they are subjective sensations of the skin, which in some cases may be attributed to the prickling and numbness which accompany an alcoholic neuritis. A quite common origin of their hallucinations is from some machine, person, or little devils in the stomach, heart, lungs, brain, etc. These ideas are freely spoken of and complained of, and reacted to by threats and often violence. Frequently these feelings give rise to hallucinations with a religious coloring, that is, spirits, God and Christ are inside of them and speak through them. The alcoholic patients in whom somatic ideas are not apt to occur are those who have gone into a stable state of simple deterioration and who have escaped the more acute hallucinatory or paranoic conditions.

One patient in a chronic hallucinatory condition suffered much from gaseous eructations which he claimed "helped to start the voices along from the stomach." During an acute hallucinatory depression another patient complained that his bowels are all stopped up and "the devil's imp is in my stomach." His ideas resembled those of other depressed psychoses. In the following statements which represent the general type of somatic delusions in alcoholic subjects, we see a distinct difference. The ideas are closely interwoven with delusions of influence, electricity, hypno- 
tism, and persecution and the reaction is one of fear, anger, threats, and violence.

"Enemies take the breath away; words are taken out of the mouth; kinetoscope works on the brain; machines take the strength away; body over-charged with electricity; rank smells come from the body; devils and spirits of hell in the stomach trying to cut out the heart; devils fly in and out of the mouth, ears, and eyes, and speak from within the body ; body full of rats; head full of cockroaches ; fire comes from the mouth," etc. These symptoms are most prominent in the acute hallucinatory conditions or in cases of protracted delirium tremens. In the chronic alcoholic psychoses, which have had a paranoic evolution, cutaneous paræsthesias of various forms, may remain which are interpreted as pains, currents, shocks, crawling of insects, pricking of needles, etc., resulting from hypnotism, electricity, etc.

GENERAL PARALYSIS.-In general paralysis the expression of somatic ideas differs markedly in form, depending on the mental condition; whether depressed or expansive, or whether in the beginning of the disease or at its height. In the beginning of general paralysis, especially the depressed states, there is a close analogy with the somatic ideas of melancholia or other depressing psychoses. They are apt to be very firm and stable and are often alluded to in a fragmentary manner after the patient has passed deep into dementia. They may be the dominating thought in the patient's mind and may have a real basis, such as an injury or disease ; they may be on a delusional or hallucinatory basis, or mere temporary result of fancy. Considerable affect may be shown in worrying or in suicidal attempts. Frequently a demented and formerly expansive general paralytic may refer to wonderful machines in his heart or body, controlling everything, sun, moon, and stars, and he may often speak of it repeatedly but it is only a form of his feeling of grandeur. He does not show the least affect. He may frequently speak of being dead or dying, but these ideas are not fixed and might readily be kindled into transitory expressions of a somatic nature. Although in general paralysis there may be a very gradual onset with depression and hypochondriacal ideas, the actual expression of somatic ideas is comparatively rare. The depressed state may be steady and progressive and if the somatic ideas appear in the onset they 
may be clung to for a long time. Gradually with dementia they drop out or perhaps later are spoken of from time to time with an affect of grandeur and expansiveness rather than the original depressed reaction.

In the following examples of somatic ideas in cases of general paralysis beginning with depression, we at once see a close resemblance to those of all other depressed affects.

The patient cannot breathe or speak; the throat is twisted; the bowels never move; stomach gone; throat plugged up; genitals wasted away; cannot sleep; hands and feet gone; saliva dried up; muscles stiff like wood; consumption of blood; shrinking away daily, etc. These delusions give no clew as to the further course of the disease, as some become rapidly demented and others go into an expansive stage.

Often the ideas have an absurd and grandiose coloring; thus a patient who became depressed after a shock in the beginning of the psychosis claimed that electricity caused the shock. He firmly believed that the electricity clutched his heart and that it was used as a switchboard; that his stomach was opened and closed by the influence of passing locomotives. In addition he claimed that there was a talking machine in his stomach from which voices emanated. (There had been excessive alcoholism.)

Another patient repeated gleefully that he was 7 feet tall and God had made him little; another had a wonderful machine in his heart which controlled sun, moon, and stars. Usually these ideas are alluded to in a fragmentary way in the course of other expansive utterances.

Paranoic Condition.-The somatic ideas resemble those of the chronic alcoholic psychoses; however, the internal organs are seldom the seat of such feelings, but the sensations are said to be "put on" the patient, etc., by some external power or influence. These ideas are closely coupled with persecutory delusions and hallucinations which give an actual pain or sensation a fantastic interpretation. Frequently they are sexual in nature and are accompanied by hallucinations of taste and smell. The reaction to these delusions is violent and threatening. The patient is surly and suspicious and shows no depressed affect. The delusions are often colored by the environment. They are permanent, but the details are changed under varying conditions. New 
[Oct.

sensations may arise and the old ones may be discarded, but as in the other delusions, the general system of the ideas is retained. Thus in a patient with well-marked persecutory delusions there developed rheumatism followed by an apoplectic attack. This was promptly referred to electrical influence. Every slight discomfort or illness in another patient was always said to be due to batteries, while at other times, no peculiar sensations could be elicited. One patient who had occasional attacks of cardiac incompensation explained the discomfort on the basis of electrical influence. The electricity was said to snap the veins in her head; it played on her heart and suffocated her; gas dried up her blood and the electricity caused salivation. In one patient there was a distinct bradycardia with attacks of syncope. At these times she complained of being crushed, put under ether, having her arteries drawn out, etc.

As a general rule these ideas vary greatly in the same individual and, if extensive, have a sexual coloring. This is exemplified in the following instance. The patient had prominent hallucinations of hearing, sight, touch, taste, and smell, and delusions of persecution and electrical influence. Her nose and mouth were burned every night by potash which was thrown into the room, heat runs through the back and stomach; she is tormented during the day by odors and pains; rank odors arise when people come near to her; she is made pregnant by wrong means and nightly the electricity causes distressing sexual feelings. These ideas are continually reacted to and the patient remains by herself much of the time.

The following tables show the frequency with which the sensations are referred to definite regions.

The viscera, bones, nerves, brain, etc., were mentioned as a seat of peculiar feelings 317 times:

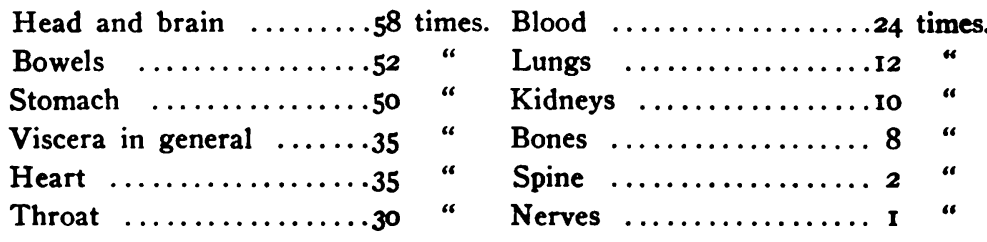


The organs of special sense and the muscular and cutaneous sensations were involved I6I times.

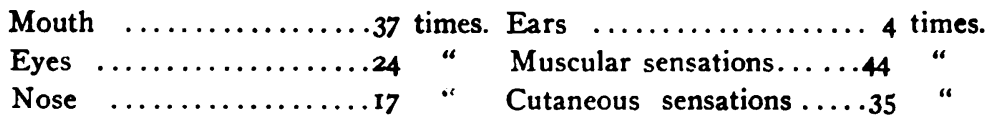

A definite disease was complained of 17 times.

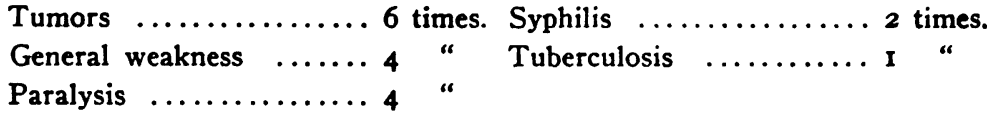

In 49 instances there was said to be an invasion of the body by animals, spirits, etc.

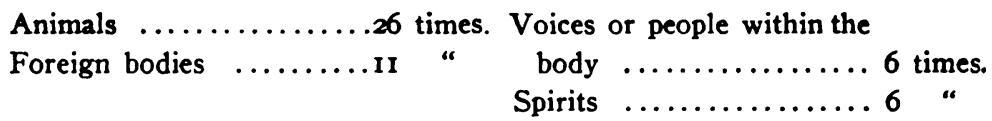

The frequency with which somatic delusions are referred to outside influences is shown in the fact that electricity, hypnotism, etc., were said to produce the sensations in 85 cases.

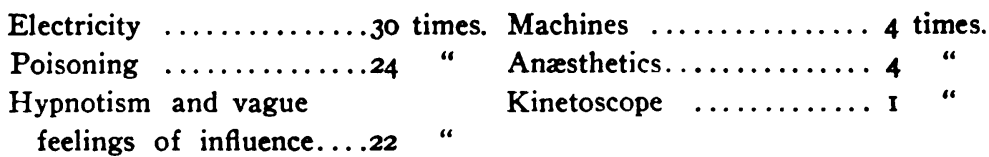

In 45 cases sensations of a sexual nature were experienced.

It is rather surprising to find that definite diseases were complained of in a comparatively small number of cases, while isolated symptoms were in such preponderance. This is better understood when we see that a large per cent of the feelings were supposed to have originated from extraneous causes and were probably experienced only when these factors were at work. In other cases the general depression was looked upon as a disease of which the somatic feelings were a symptom or cause. The patients as a rule have lost the ability to analyze and criticise the obsessions and to associate the feelings properly, and abandon themselves completely to the prepossessing ideas. This predominent idea becomes fixed and cannot be dislodged from the consciousness,-a state which Ribot calls hypertrophy of attention. 
It is not an uncommon experience to find unilateral hallucinations of hearing, affecting the diseased ear in cases of onesided deafness in which the peripheral irritation undoubtedly excites the hallucinations. These hallucinations often disappear under local treatment; however, from everyday experience it is seen that such examples are in the minority and many hallucinations have undoubtedly a central origin. If we find no peripheral cause for hypochondriacal ideas, we may consider many of these as sensations likewise projected from the center.

Cases of actual hypochondria with feelings of double personality and peculiar muscular sensations are rare and may be based on a disturbance of the cœnæsthesia with delusions centering about the patient's body. The body is not altered by excitement or depression, but if it persists a new psychical and mental state is produced. The graver forms of somatic ideas gradually merge into double personality and délire de negation.

For a psychological analysis of hypochondriacal ideas, with especial reference to the disturbance of cœnæsthesia, the reader is referred to the article of G. Deny and P. Camus (II). They point out that the sensory perceptions have the organic sensations for an indispensable concomitant. A suppression or nonutilization by the consciousness of a group of these organic sensations (muscular, visceral, articular), resulting from a disturbance of association, is sufficient to bring about in our cœnæsthesia, a more or less profound perturbation which may go on to a single doubt, or to a complete negation of our bodily existence. 
GENERAL SUMMARY.

\begin{tabular}{|c|c|c|c|}
\hline Prychosis. & $\begin{array}{l}\text { Per cent } \\
\text { showing } \\
\text { somatic } \\
\text { ideas. }\end{array}$ & $\begin{array}{l}\text { Relation of somatic ideas } \\
\text { to physical condition. }\end{array}$ & $\begin{array}{l}\text { Reaction of the patient } \\
\text { to the somatic idea. }\end{array}$ \\
\hline Melancholis & $80.76 \%$ & $\begin{array}{l}\text { Bodily disease often } \\
\text { fundamental; onset } \\
\text { less often insidious, } \\
\text { rarely on delusional } \\
\text { basis. }\end{array}$ & $\begin{array}{l}\text { Sadness, depression, } \\
\text { worry, anxiety, hope- } \\
\text { lessness, despair. }\end{array}$ \\
\hline $\begin{array}{l}\text { Paranoic condi- } \\
\text { tion }\end{array}$ & $26.11 \%$ & $\begin{array}{l}\text { Rare physical founda- } \\
\text { tion; occasionally de- } \\
\text { pendent on parasthe } \\
\text { Bias; usually variable } \\
\text { and on delusional } \\
\text { basis. }\end{array}$ & $\begin{array}{l}\text { Suspicion, scolding, } \\
\text { irritability, threaten- } \\
\text { Ing and violent. }\end{array}$ \\
\hline Dementia præcox & $22.40 \%$ & $\begin{array}{c}\text { Rare physical etiology; } \\
\text { often insidious onset; } \\
\text { usually on delusional } \\
\text { basis, variable and } \\
\text { absurd, often refer- } \\
\text { able to masturbation. }\end{array}$ & $\begin{array}{l}\text { If on delusional basis, } \\
\text { anger, threats, vio- } \\
\text { lence and obscenity; } \\
\text { less often worry and } \\
\text { depression; usaally } \\
\text { reaction inadequate; } \\
\text { indifferent, silly, at } \\
\text { times apathetic and } \\
\text { scolding. }\end{array}$ \\
\hline $\begin{array}{l}\text { Alcoholic p8y- } \\
\text { choses (chiefly } \\
\text { paranoic) }\end{array}$ & $17.92 \%$ & $\begin{array}{l}\text { Often dependent on } \\
\text { gastric disturbances, } \\
\text { neuritic disorders, } \\
\text { paræsthesias, etc., } \\
\text { nsually explained on } \\
\text { delusional basis. }\end{array}$ & $\begin{array}{l}\text { Fear, scolding, threaten- } \\
\text { ing and violent. }\end{array}$ \\
\hline $\begin{array}{l}\text { General paralysis } \\
\text { (with onset of } \\
\text { depression) }\end{array}$ & $9.42 \%$ & $\begin{array}{l}\text { Resembles melancholia. } \\
\text { Later may be gran- } \\
\text { diose and fragmen- } \\
\text { tary. }\end{array}$ & $\begin{array}{l}\text { At onsct worry and } \\
\text { depression. If gran- } \\
\text { diose, exaltation and } \\
\text { eupboria. }\end{array}$ \\
\hline $\begin{array}{c}\text { Manic depressive } \\
\text { insanity (de- } \\
\text { pressed phases) }\end{array}$ & $\cdots$ & $\begin{array}{c}\text { When present are apt } \\
\text { to bear direct relation } \\
\text { to some occurrence } \\
\text { or physical disease. }\end{array}$ & $\begin{array}{l}\text { Depression, sadness, } \\
\text { worry, hopelessness. }\end{array}$ \\
\hline
\end{tabular}




\section{BIBLIOGRAPHY}

I. Ribot.-The Psychology of the Emotions. 1897, p. 26.

2. Head, Henry.-Certain Mental Changes that Accompany Visceral Disease. Brain, Vol. XXIV, p. 345.

3. Fischer, J.-Ueber Psychosen bei Herzkranken. Allg. Zeitsch. f. Psych., Vol. LIV, p. 1048.

4. Krafft-Ebing, R. v.-Nervösität und Neurasthenische Zustände, I895. 5. Kiernan, Jos. G.-Interaction of Somatic and Psychic Disorders. Alienist and Neurologist, Vol. XVIII, p. 28, 1897.

6. Mayer, C. E. Louis.-Die Beziehungen der krankhaften Zustände und Vorgänge in den Sexual-Organen des Weibes zu Geistesstörungen. 1869.

7. Klein.-Ann. Med. Psych., Vol. VII, p. 437, 1888.

8. Wollenberg, R.-Die Hypochondrie. Nothnagel's Specielle Pathologie und Therapie, Bd. XII, I. Theil, III Abtheilung.

9. Parrish, Edmund.-Hallucinations and Delusions. $\quad 1897$.

10. Ribot, T.-Diseases of Personality. I895.

Ir. Deny, G., and Camus, P.-Sur une Form d'Hypochondrie Aberrante due à la Perte de la Conscience du Corps. Rev. Neur., May 15, 1905. 